\title{
REDBEDS AND THERMOVISCOUS MAGNETIZATION THEORY
}

Dennis V. Kent and John D. Miller

Lamont-Doherty Geological Observatory and Department of Geological Sciences, Columbia University

Abstract. Thermal demagnetization characteristics of a Brunhes-age viscous overprint in Appalachian redbeds and a thermoviscous component acquired in the laboratory at moderate temperature agree well with relaxation time-blocking temperature relations for hematite proposed by Pullaiah et al. [1975]. Supporting evidence was obtained from redbeds associated with an igneous dike intrusion although the interpretation of these data are complicated by magnetochemical alterations. Paradoxically, experimental data for magnetite in some limestones were shown to agree more closely with an alternative theory of Walton [1980]. The hematite in redbeds is predominant1y singledomain (SD) whereas magnetite in the 1imestones studied extends well into the multidomain (MD) range. Thus experiment and theory could be reconciled if it is assumed that Pullaiah et a1. applies strictly to SD material whereas Walton's theory somehow describes thermoviscous effects dominated by larger MD grains.

\section{Introduction}

The importance of remagnetization has become more widely recognized in the interpretation of the paleomagnetic record but the mechanism of partial to complete overprinting is usually difficult to ascertain. A fundamental process leading to remagnetization in a geological context is of thermoviscous nature, due to the enhanced activation of grain magnetic moments with prolonged exposure to the geomagnetic field. especially at moderate temperatures associated with burial. Thus the contribution of thermoviscous effects needs to be taken into account before a stable secondary component of magnetization can be confidently attributed to some other cause, for example, a chemical remanent magnetization for which evidence is typically more indirect.

There are presently two competing sets of theoretical relationships for assemblages of SD magnetite and hematite grains that can be used to evaluate relaxation time-blocking temperature ( $t-$ T) effects on magnetizations. Pullaiah et al. [1975] published $t-T$ curves derived for assemblages of identical SD grains, based on the relation

$$
\frac{\ln \left(c t_{1}\right)}{\ln \left(c t_{2}\right)}=\frac{T_{2} J_{s}{ }^{n}\left(T_{1}\right)}{T_{1} J_{s}{ }^{n}\left(T_{2}\right)}
$$

where $c$ is the frequency factor $\left(10^{10} \mathrm{sec}^{-1}\right)$ and $n$ is the exponent that includes coercivity as a function of the temperature dependence of the spontaneous magnetization $\left(\mathrm{J}_{\mathrm{s}}\right)$; Pullaiah et al.

Copyright 1987 by the American Geophysical Union.

Paper number 6L7118.

$0094-8276 / 87 / 006 \mathrm{~L}-7118 \$ 03.00$
[1975] set $n=2$ for magnetite and $n=4$ for hematite.

Walton [1980] proposed an alternative relation

$$
\left[\frac{\ln \left(c t_{1}\right)}{\ln \left(c t_{2}\right)}\right]^{3+r}=\left[\frac{T_{2} J_{s}{ }^{n}\left(T_{1}\right)}{T_{1} J_{s}{ }^{n}\left(T_{2}\right)}\right]^{2+r}
$$

which Middleton and Schmidt [1982] evaluated for magnetite and hematite by setting $r=-1$ for approximately lognormal SD grainsize distributions and othervise using the same constants and temperature-dependencies as Pullaiah et $\mathrm{al}$. [1975]. The $t-T$ curves for hematite for the respective theories are compared in Figure 1.

It has been shown [Rent, 1985] that therma1 activation processes are more potent in some magnetite-bearing limestones than the expression derived by Pullaiah et a1. [1975] allows. The purpose of this paper is to test the two alternative $t-T$ models for hematite by comparison with experimental observations on redbeds.

\section{Fie1d and Laboratory Tests}

For the Appalachian redbed units studied here, we have confirmed the absence of magnetite and the predominant presence of hematite by IRM acquisition (e.g., Figure 8 in Kent and Opdyke, 1985 ) and thermal demagnetization spectra ansiyses. In order to test the $t-T$ models, one must isolate a thermoviscous component of known origin. One such component is a viscous overprint along the present Earth's field (PEF) which we assume to have been acquired over no longer than $0.73 \mathrm{Ma}$ (duration of Brunhes Normal Polarity Chron) at ambient temperature $\left(20^{\circ} \mathrm{C}\right)$. To extend the temperature range of observation, we have compared demagnetization characteristics with the calculated thermal history of redbeds intruded by an igneous dike, and more directly, performed a laboratory acquisition experiment at elevated temperature.

\section{Present Earth's field overprint}

We have thermally demagnetized a representative set of samples from the Lower Carboniferous Mauch Chunk, Upper Devonian Catski11 and Upper Silurian Bloomsburg redbeds at $25^{\circ} \mathrm{C}$ temperature intervals (effective laboratory heating time of $300 \mathrm{sec}$ ) to determine the maximum unblocking temperature of the PEF component. A prominent and wel1-defined PEF component was isolated in samples of the Catskill from the Breezewood ( $\mathrm{Pa}$. ) area [Miller and Kent, 1986]. The maximum unblocking temperature for this component $\left(D=347^{\circ}, I=65^{\circ}, a 95=4^{\circ}\right.$ for $n=16$ samples) is $275^{\circ} \pm$ $25^{\circ} \mathrm{C}$ (Figure $2 \mathrm{a}$ ). The PEF component in 10 samples from the Mauch Chunk and 9 samples from the Bloomsburg analyzed was typically small, as 


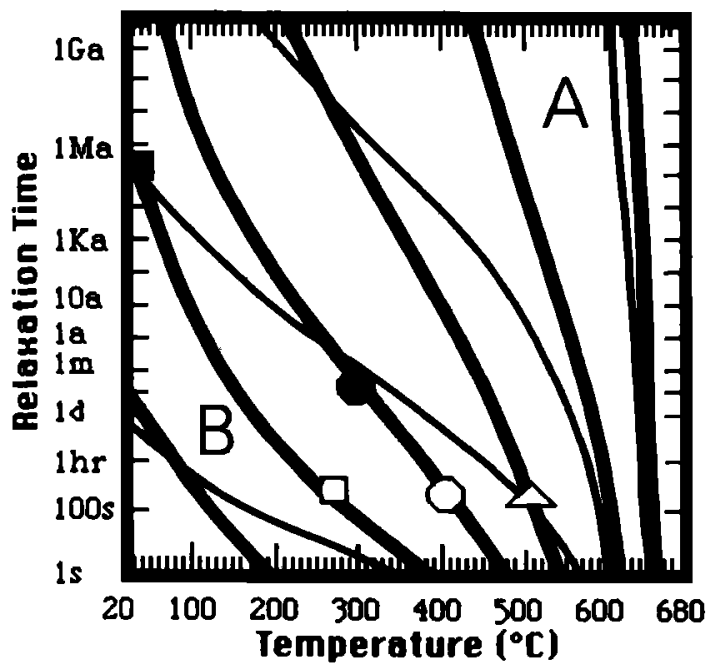

Figure 1. Relaxation time-blocking temperature curves for hematite. Heavy lines, based on Pullaiah et al. [1975]; 1ighter 1ines, based on Walton [1980] as calculated by Middleton and Schmidt [1982]. Filled square and circle are $t-T$ conditions for acquisition of a Brunhes viscous overprint and for laboratory heating experiment. respectively; open square and circle are the corresponding laboratory unblocking conditions, in each case the observed is the same as predicted by Pullaiah et a1. [1975]. Open triangle is laboratory unblocking condition for both a Brunhes viscous overprint and for the laboratory heating experiment predicted by Middleton and Schmidt [1982].

already indicated in lower resolution data [Kent and Opdyke, 1985; Kent, 1986], but had a maximum unblocking temperature $\left(250^{\circ} \mathrm{C}\right)$ similar to the better determined Catskill results.

\section{Igneous dike intrusion}

We sampled the Duncannon Member of the Catskill Formation near to its contact with a near-vertical, $15.5 \mathrm{~m}$ wide, Triassic/Jurassic dike in railroad cut near US 22 on the east bank of the Susquehanna River. Three samples were taken form the dike itself. Seven samples from the Catskill redbeds were taken extending from the blackened contact aureole to about $27 \mathrm{~m}$ (1.73 dike widths, $d w$ ) measured from the center and perpendicular to the strike of the dike.

Redbeds in the contact aureole were totally overprinted and had unicomponent magnetizations similar to that of the dike $\left(D=16^{\circ}, I=45^{\circ}\right)$. Demagnetization of the remainder of the samples revealed two components of magnetization, a low to moderate unblocking temperature Triassic/ Jurassic overprint and a high unblocking temperature component of clear1y Paleozoic (Kiaman) age (Figure 2b).

\section{Laboratory acquisition}

Redbed samples from the Mauch Chunk and Catski11, chosen on the basis of small susceptibility changes with thermal demagnetization in companion specimens, were heated in the NRM state at $300^{\circ} \mathrm{C}$ for 11 days while exposed in known orientation to the ambient magnetic field in the laboratory $(0.06 \mathrm{mT})$. The 1aboratory-acquired remanence component was readily resolved in al1 4 samples by subsequent progressive thermal demagnetization at $25^{\circ} \mathrm{C}$ steps from $275^{\circ} \mathrm{C}$; maximum unblocking temperatures for this component were about $400^{\circ}\left( \pm 25^{\circ} \mathrm{C}\right)$ (Figure $2 \mathrm{c}$ ).

\section{Analysis of Results}

The maximum unblocking temperature for the PEF component in the hematite-bearing redbeds studied here is consistently in the range $250^{\circ}$ to $300^{\circ}$. According to the $t-T$ relations of Pullaiah et al. [1975], this would correspond to acquisition of a viscous remanence acquired at ambient temperature over about $10^{6}$ years (Figure 1). consistent with our suppositon that this component was acquired over the Brunhes. In contrast, the Middleton and Schmidt [1982] curves suggest that the expected Brunhes-age VRM would require laboratory demagnetization temperatures as high as $500^{\circ} \mathrm{C}$.

If the dike-related overprint in the redbeds is purely of thermoviscous origin, then the maximum exposure temperatures predicted by an appropriate $t-T$ theory from the laboratory unblocking data should conform to the independently determined thermal history of the igneous intrusive event. This thermal history was modeled by the formulation of Harrison and Clarke [1979], using an intrusion temperature of $1150^{\circ} \mathrm{C}$ and a $13 \%$ contribution from the latent heat of crystallization. The thermal pulse in the country rocks in a conductive regime would have been within $25^{\circ} \mathrm{C}$ of the maximum temperature for between $2 \times 10^{7}$ sec at $1.06 \mathrm{dw}$ to $6 \times 10^{7} \mathrm{sec}$ at $1.73 \mathrm{dw}$, and we take this as the criterion for defining exposure times. The predicted peak exposure temperatures calculated according to Pullaiah et al.'s (eq. 1) and Walton's (eq. 2) theories are compared to the temperature profiles determined from the simple conductive thermal model in Figure 3.

The dike overprint unblocking temperatures for the two samples at 1.06 and $1.22 \mathrm{dw}$ are near $600^{\circ} \mathrm{C}$. Because this is in the so-called A region of either mode1 (Figure 1), where duration of heating is not a strong factor, a similarly high exposure temperature would be predicted. Such a high exposure temperature is not plausible and chemical effects associated with the dike intrusion had most likely resulted in the elevation of the overprint. For the 3 samples that were farthest from the dike (at 1.33, 1.51 and 1.73 dw) and therefore possibly less chemically altered, the peak exposure temperatures predicted by the Pullaiah et a1. model for the dike overprints are in resonable agreement with a modeled temperature profile (Figure 3). Chemical alteration cannot explain the anomalous1y low temperature predictions derived from the Middleton and Schmidt curves for these same samples because it would tend to act in the opposite direction, to raise the overprint unblocking temperature as in the blackened aureole, but we cannot exclude the possibility of reduced exposure temperatures due to rapid convective heat loss closer to the dike.

A more decisive test of the $t-T$ theories at higher temperatures comes from the laboratory acquisition experiment. The Pullaiah et al. [1975] mode1 predicts removal temperatures of $400^{\circ} \mathrm{C}$, whereas the Middleton and Schmidt [1982] 


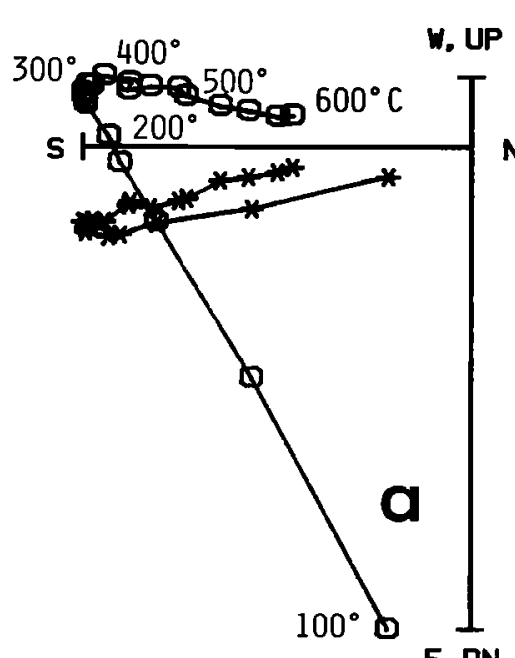

E, DN

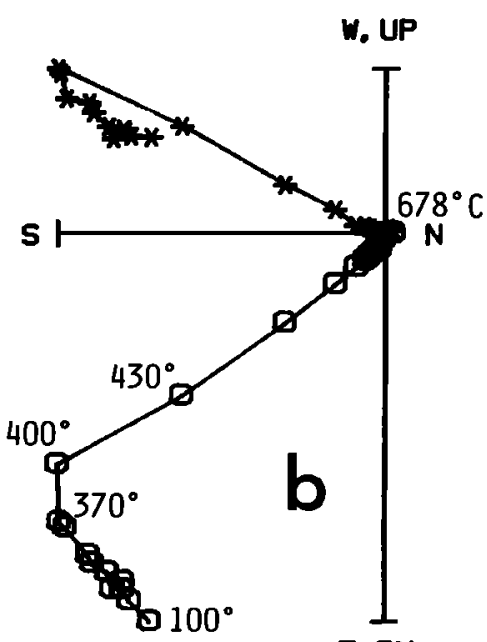

E. DN

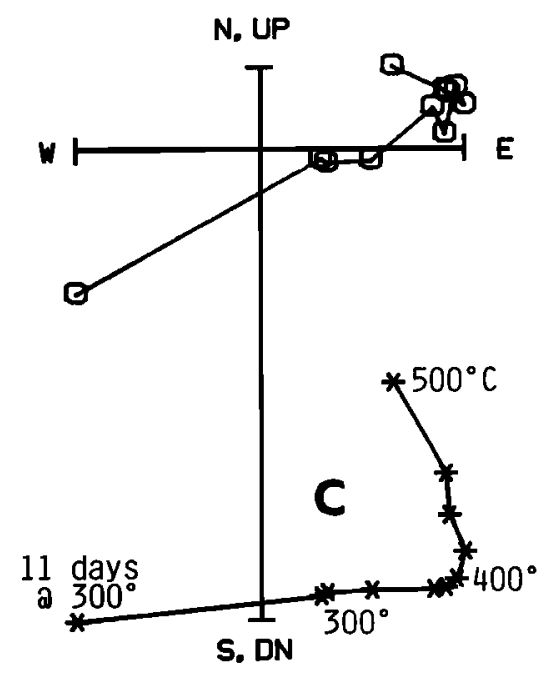

$\longrightarrow=1 \mathrm{~mA} / \mathrm{M}$

$H=.1 \mathrm{~mA} / \mathrm{M}$

$\longmapsto=10 \mathrm{~mA} / \mathrm{M}$

Figure 2. Orthogonal vector end-point diagrams for thermal demagnetization (open circles/stars plotted on vertical/horizontal projection in geographic coordinates). a) NRM of representative Appalachian redbed sample from Upper Devonian Catskill Fm.; the northerly and down magnetization removed in the initial stages of demagnetization to about $275^{\circ} \mathrm{C}$ is interpreted to represent a viscous remanence acquired in the PEF over the Brunhes. b) NRM of Catskill redbed sample taken $1.73 \mathrm{dw}$ from the center of a $15.5 \mathrm{~m}$ wide Triassic/Jurassic igneous dike; dike overprint component is revealed to $400^{\circ} \mathrm{C}$ treatment, Paleozoic direction from $430^{\circ} \mathrm{C}$ to near origin $\left(678^{\circ} \mathrm{C}\right)$. c) Mauch Chunk redbed sample heated in the laboratory for 11 days at $300^{\circ} \mathrm{C}$ while exposed to Earth's field; laboratory-produced overprint revealed to $400^{\circ} \mathrm{C}$ treatment, Paleozoic direction thereafter.

curves predict over $500^{\circ} \mathrm{C}$, compared to the observed $400^{\circ} \mathrm{C}$ for the laboratory acquired magnetization (Figure 1).

\section{Discussion}

The various field and laboratory tests presented here strongly favor the Pullaiah et al. [1975] model for thermoviscous magnetization in hematite-bearing rocks. For the PEF viscous overprints and leborstory acquisition experiments, our observations agree remarkably we11 with the Pullaiah et al. predictions, but disagree by up to $250^{\circ} \mathrm{C}$ from the higher removal temperatures called for by the Middleton and Schmidt [1982] curves for hematite. The results from the igneous dike intrusion are more ambiguous and emphasize the potential importance of chemical alteration in assessments of thermoviscous contributions, especially at more elevated temperatures as suggested by Pullaiah et a1. [1975].

The excellent agreement we find with Pullaiah et a1. [1975] for hemetite contrasts with the experimental data for some magnetite-bearing rocks which were previously shown to be in much better accord with Walton [1980]. The explanation for this apparent paradox may have to do with the different domain states of the magnetite and hematite in the rocks studied. For the redbed magnetizations, we are virtually assured that the dominant contribution comes from SD hematite: the SD-MD threshold diameter for hematite of approximately 2000 micrometers [Stacey, 1963] puts MD grains into the pebble size range, above the silty (<62.5 micrometers) to sandy ( 2000 micrometers) textures of redbeds typically sampled in paleomagnetic studies. Thus the agreement of the experimental data on thermoviscous magnetization in hematite with Pullaiah et al. [1975] strong1y suggests that this $t-T$ theory is appropriate for SD magnetizations.

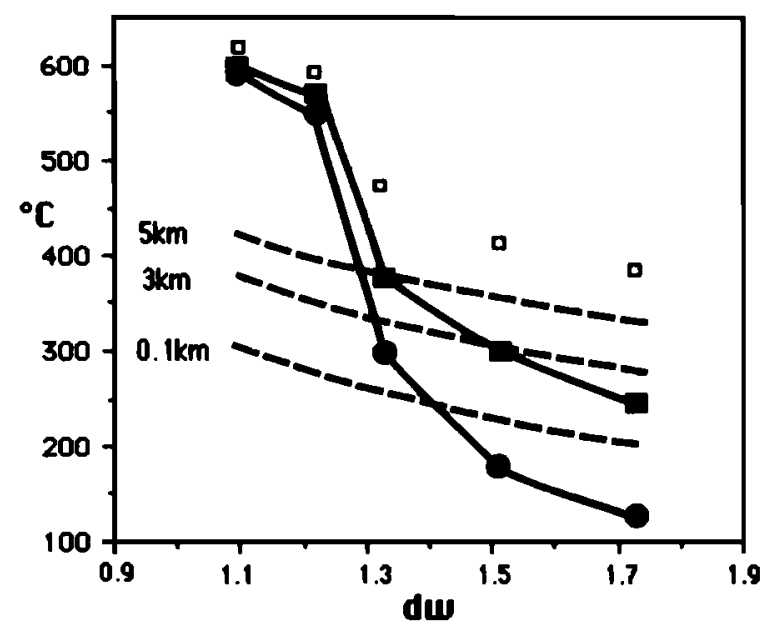

Figure 3. Temperature estimates related to igneous dike intrusion. Dashed lines are conductive thermal models for igneous dike of $15.5 \mathrm{~m}$ width, assuming different depths of intrusion $\left(25^{\circ} \mathrm{C} / \mathrm{km}\right)$. Darker lines joining filled squares and circles are maximum temperatures predicted by Pullaiah et al. [1975] and Middleton and Schmidt [1982] curves for hematite, respectively, based on maximum unblocking temperature of dike overprints in Catskill redbed samples (open squares) at different distances (expressed in terms of $d w$ ) from center of the dike. 
In contrast to hematite, the very small upper size limit of SD behavior in magnetite (of less than 0.1 micrometers) means that larger, MD grains of magnetite are very likely to be present in rocks, as observed directly in the limestones [McCabe et a1., 1982]. The suggestion that Walton's theory in some way describes thermoviscous magnetizations dominated by MD behavior, made on the basis of the good agreement of experimental data for magnetite [Kent, 1985], is supported by the poor agreement found for SD hematite. It is possible, for example, that the distribution parameter $(r)$ in this theory is more related to the nature of domain wall motions rather than the distribution of grain size per se.

We therefore speculate that the disparity between the alternate $t-T$ relations might be reconciled if the Pullaiah et al. [1975] model is strict1y applicable on $1 y$ to SD grains whereas the t-T curves calculated by Middleton and Schmidt [1982] from Walton's [1980] derivation in fact better describe thermoviscous behavior in MD material. Since hematite almost always is expected to occur in the SD size range in rocks of paleomagnetic interest, the $t-T$ relations for hematite proposed by Pullaiah et al. [1975] may be universally applicable (barring chemical effects). For magnetite, Walton's [1980] theory appears to agree with relevant observations for rocks with abundant MD magnetite such as the limestones, but we might expect that those rocks that are demonstrably dominated by SD magnetite should have thermoviscous behavior that is more compatible with Pullaiah et a1. [1975]. Confirmation of this prediction would provide impetus to explore the physical implications of Walton's theory, which now are rather obscure to us, especially in regard to MD magnetization.

In practical terms, the widespread PermoCarboniferous remagnetizations observed in Appalachian redbeds cannot be explained by thermal processes alone, regardless of the formulation used [Pullaiah et al. or Walton], because of the high $\left(660^{\circ} \mathrm{C}\right.$ plus) unblocking temperatures observed [e.g., Kent and Opdyke, 1985; Miller and Kent, 1986]. However, the choice of theory becomes more critical when maximum unblocking temperatures are lower. An example is the study of the thermal history of the Sidney Basin [Middleton and Schmidt, 1982], in which the paleothermometry was delineated in part by the crossover between the $t-T$ curves for secondary magnetizations carried by magnetite and hematite using Walton's theory. If the model of Pullaiah et $a 1$. is instead used for hematite, then the $t-T$ curves are essentially parallel and nonintersecting, thus implying that these secondary magnetizations lack a common thermal origin.
Acknowledgements. We thank D. A. Schneider for field assistance and for programming the dike cooling model, S. L. Halgedahl for stimulating discussions, and both for constructive criticisms of the manuscript. Work supported by National Science Foundation Earth Sciences grant EAR8507046. Lamont-Doherty Geological Observatory Contribution \#4112.

\section{References}

Harrison, M.T. and G. K.C. Clarke, A model of the termal effects of igneous intrusion and up1ift as applied to Quottoon pluton, British Columbia, Can. J. Earth Sci.,16, 411$420,1979$.

Kent, D.V., Thermoviscous remagnetization in some Appalachian 1imestones, Geophys. Res. Lett., 12. 805-808, 1985.

Kent, D.v., Separation of prefolding and secondary magnetizations from the Bloomsburg Formation from the southern 1imb of the Pennsylvania Reentrant (Abs.), EOS,67, 170, 1986.

Kent, D.V. and N.D. Opdyke, Mu1ticomponent magnetizations from the Mississippian Mauch Chunk Formation of the central Appalachians and their tectonic implications, J. Geophys. Res.,90, 5371-5383, 1985.

McCabe, C., R. Van der Voo, D.R. Peacor, C.R. Scotese and R. Freeman, Diagenetic magnetite carries ancient yet secondary remanence in some Paleozoic sedimentary carbonates, Geology,11, 221-223, 1983.

Middleton, M.F. and P.W. Schmidt, Paleothermometry of the Sydney Basin. J. Geophys. Res.. 87, 5351-5359, 1982.

Miller, J.D. and D.V. Kent, Paleomagnetism of the Upper Devonian Catskill Eormation from the southern limb of the Pennsylvania salient: Possible evidence of oroclinal rotation, Geophys. Res, Lett., 1986.

Pullaiah, G., E. Irving, K.L. Buchan and D.J. Dunlop. Magnetization changes caused by burial and uplift, Earth and P1anet. Sci. Lett., 28, 122-143, 1975.

Stacey. F.D., The physical theory of rock magnetism. Adv. Phys.., 12, 45-133, 1963.

Walton, D., Time-temperature relations in the magnetization of assemblies of single domain grains, Nature, 286, 245-247, 1982.

D. V. Kent and J. D. Miller, Lamont-Doherty Geological Observatory and Department of Geological Sciences, Columbia University, Palisades, NY 10964.

(Received December 11, 1986; revised February 2, 1987; accepted February 2, 1987.) 